\title{
Endothelial Progenitor Cells and Percutaneous Coronary Artery Intervention
}

\author{
Editorial to: "Effect of High Dose Statin Pretreatment on Endothelial Progenitor Cells \\ after Percutaneous Coronary Intervention (HIPOCRATES Study)" by A. Eisen et al.
}

\author{
Carlo Briguori • Cristina Quintavalle • \\ Giovanni Napolitano • Gerolama Condorelli
}

Published online: 25 February 2015

(C) Springer Science+Business Media New York 2015

In the HIPOCRATES study Eisen et al. give us important insighths into the effects of statins on endothelial progenitor cells (EPC) levels after percutaneous coronary intervention (PCI) [1]. Pretreatment with high-dose statins given before PCI induces an increase in EPC. In the last decade the understanding of EPC has grown, supporting the important role of these cells for vascular health and adding impetus to the search for ways to upregulate their circulating levels. Although it is clear that the contribution to vascular healing of these circulating progenitors is almost certainly due to their paracrine effects, it is also evident that their function is dependent on both the local microenvironment and a synergy between other populations mobilized in response to the vascular insult.

In the mid 1990s Risau et al. [2] described the origins of endothelial cells within the embryonic vasculogenesis, finding that the endothelial cells derive from a putative common mesenchymal precursor for endothelium and hematopoietic cells

C. Briguori

Laboratory of Interventional Cardiology, Clinica Mediterranea,

Naples, Italy

C. Quintavalle · G. Condorelli

Department of Molecular Medicine and Medical Biotechnology,

"Federico II" University of Naples, and IEOS, CNR, Naples, Italy

G. Napolitano

Ospedale San Giuliano, Naples, Italy

C. Briguori $(\square)$

Interventional Cardiology, Clinica Mediterranea, Via Orazio, 2, 80121 Naples, Italy

e-mail: carlobriguori@clinicamediterranea.it named the hemangioblast. In 1997 Asahara and colleagues published a landmark paper [3] showing that bone marrowderived CD34+ VEGFR-2+ monocytic cells could be isolated from human blood and grown in culture under conditions that yielded cells with endothelial characteristics indicating the contribution of bone marrow-derived putative EPC to adult neoangiogenesis. Two major cell types may be obtained from peripheral blood mononuclear cells: 1) the early-outgrowth EPC, obtained by culturing isolated mononuclear cells for 4-7 days, and 2) the late-outgrowth EPC, that start proliferating only after 2-3 weeks in culture [4]. The early-outgrowth EPC origin from haematopoietic lineage, have a limited proliferative capacity and, differently from mature endothelial cells, present similar features to monocytes since they express the monocytic marker CD14 and the panleucocytic marker CD45 [5]. The early-outgrowth EPCs may have a role as biomarkers. The late out-growth EPC (also called endothelial colony-forming cells [ECFC]) express the endothelial (KDR, CD146 and VE-cadherin), but not the haematopoietic (CD45 and CD14) markers. The late-outgrowth EPC proliferate can form a vascular network, and are probably more related to replacement of defective endothelial cells and vasculogenesis. Circulating late-outgrowth EPC represent $<1 \%$ of circulating EPC and are a smaller part of the CD34-positive bone marrow cells used in clinical trials [6]. The level of circulating EPC is low in normal conditions but it rapidly increases in response to physiological and pathological stimuli, including myocardial and peripheral ischemia [7]. The EPC move from the bone marrow and travel to the sites of new vessel growth in the ischemic tissue (injury site): this process called "homing" [8] includes a coordinated sequence of multi-step adhesive and signaling events, including chemoattraction, adhesion, and migration. Some studies report that the EPC number is 
reduced in patients with atherosclerotic disease [9] and that a reduced number of EPCs is associated with the occurrence of ischemic cardiovascular events in patients with angiographically documented CAD $[10,11]$.

The endothelial damage caused by balloon inflation and/or stent implantation give rise to an intensive local inflammatory response, resulting in neointimal hyperplasia, in-stent restenosis and potentially acute stent thrombosis. Recruitment of EPC to the site of vascular injury has been proposed to promote vascular healing and has been shown to inhibit neointimal proliferation and restenosis associated with PCI [12]. On the contrary, however, Schober et al [13] demonstrated a relationship between the increase in $\mathrm{CD} 34^{+}$cells and the risk of restenosis. Therapies focused on EPC and/or the homing process to the site of stent implantation are attractive and have the potential to improve clinical outcomes after PCI. The mechanisms responsible for the mobilization of EPC have been reviewed extensively elsewhere [14]. Among their pleiotropic effects statins are able to mobilize $\mathrm{CD} 34^{+}$and $\mathrm{KDR}^{+}$cells into the peripheral circulation in a dose-dependent manner. Statins also increase the formation of ECFC $[15,16]$ and can induce in vitro differentiation of $\mathrm{CD} 14^{+}$and $\mathrm{CD} 34^{+}$cells toward an endothelial phenotype [17]. Walter et al. [18] demonstrated an accelerated rate of re-endothelialization and a reduction in neointimal hyperplasia in rats treated with simvastatin after balloon mediated arterial injury.

Further studies are required to elucidate how to use EPC as an effective treatment modality, evaluating not only the target cell type of interest, but also the involvement of the microenvironment on cellular behavior, the best mode of delivery of cells and defined paracrine factors to the site of injury and the need for adjunctive therapy to optimize EPC function. All strategies effective in increasing the EPC level should be tested in order to assess whether they are useful in reducing disease progression and therefore events at follow-up.

\section{References}

1. Eisen A, Leshem-Lev D, Yavin H, et al. Effect of high dose statin pretreatment on endothelial progenitor cells after percutaneous coronary intervention (HIPOCRATES study). Cardiovasc Drugs Ther 2015;29: this issue.
2. Risau W, Flamme I. Vasculogenesis. Ann Rev Cell Dev Bi. 1995;11: 73-91.

3. Asahara T, Murohara T, Sullivan A, et al. Isolation of putative progenitor endothelial cells for angiogenesis. Science. 1997;275:964-6.

4. Timmermans F, Plum J, Yöder MC, Ingram DA, Vandekerckhove B, Case J. Endothelial progenitor cells: identity defined? J Cell Mol Med. 2009;13:87-102.

5. Hur J, Yoon C-H, Kim H-S, et al. Characterization of two types of endothelial progenitor cells and their different contributions to neovasculogenesis. Arterioscl Throm Vas. 2004;24:288-93.

6. Prater DN, Case J, Ingram DA, Yoder MC. Working hypothesis to redefine endothelial progenitor cells. Leukemia. 2007;21:1141-9.

7. Masuda H, Kalka C, Takahashi T, et al. Estrogen-mediated endothelial progenitor cell biology and kinetics for physiological postnatal vasculogenesis. Circ Res. 2007;101:598-606.

8. Asahara T, Masuda H, Takahashi T, et al. Bone marrow origin of endothelial progenitor cells responsible for postnatal vasculogenesis in physiological and pathological neovascularization. Circ Res. 1999;85:221-8.

9. Vasa M, Fichtlscherer S, Adler K, et al. Increase in circulating endothelial progenitor cells by statin therapy in patients with stable coronary artery disease. Circulation. 2001;103:2885-90.

10. Schmidt-Lucke C, Rossig L, Fichtlscherer S, et al. Reduced number of circulating endothelial progenitor cells predicts future cardiovascular events: proof of concept for the clinical importance of endogenous vascular repair. Circulation. 2005;111:2981-7.

11. Briguori C, Testa U, Riccioni R, et al. Correlations between progression of coronary artery disease and circulating endothelial progenitor cells. FASEB J. 2010;24:1981-8.

12. Kipshidze N, Dangas G, Tsapenko M, et al. Role of the endothelium in modulating neointimal formation: vasculoprotective approaches to attenuate restenosis after percutaneous coronary interventions. J Am Coll Cardiol. 2004;44:733-9.

13. Schober A, Hoffmann R, Opree N, et al. Peripheral CD34+ cells and the risk of in-stent restenosis in patients with coronary heart disease. Am J Cardiol. 2005;96:1116-22.

14. Leone AM, Valgimigli M, Giannico MB, et al. From bone marrow to the arterial wall: the ongoing tale of endothelial progenitor cells. Eur Heart J. 2009;30:890-9.

15. Llevadot J, Murasawa S, Kureishi Y, et al. HMG-CoA reductase inhibitor mobilizes bone marrow "derived endothelial progenitor cells. J Clin Invest. 2001;108:399-405.

16. Deschaseaux F, Selmani Z, Falcoz P-E, et al. Two types of circulating endothelial progenitor cells in patients receiving long term therapy by HMG-CoA reductase inhibitors. Eur J Pharmacol. 2007;562:111-8.

17. Dimmeler S, Aicher A, Vasa M, et al. HMG-CoA reductase inhibitors (statins) increase endothelial progenitor cells via the PI 3-kinase/Akt pathway. J Clin Invest. 2001;108:391-7.

18. Walter DH, Rittig K, Bahlmann FH, et al. Statin therapy accelerates reendothelialization: a novel effect involving mobilization and incorporation of bone marrow-derived endothelial progenitor cells. Circulation. 2002; 105:3017-24. 